\title{
Análise ultraestrutural da interação de Curtobacterium flaccumfaciens pv. flaccumfaciens em genótipos de feijoeiro
}

\author{
Valmir Luiz de Souza ${ }^{1}$, Antonio Carlos Maringoni²
}

\begin{abstract}
${ }^{1}$ Agência Paulista de Tecnologia dos Agronegócios, APTA, Avenida Alcides Fagundes Chagas s/n, CEP 16.055-240, Araçatuba, SP, email: vlsouza@ aptaregional.sp.gov.br; ${ }^{2}$ Faculdade de Ciências Agronômicas, UNESP, Departamento de Produção Vegetal, CP 237, CEP 18.603-970, Botucatu, SP.
\end{abstract}

Autor para correspondência: Valmir Luiz de Souza.

Data de chegada: 19/01/2006. Aceito para publicação em: 16/10/2008

\section{RESUMO}

Souza, V.L; Maringoni, A.C.. Análise ultraestrutural da interação de Curtobacterium flaccumfaciens pv. flaccumfaciens em genótipos de feijoeiro. Summa Phytopathologica, v.34, n.4, p.318-320, 2008

Observações com microscopia eletrônica de transmissão em secções ultrafinas de células de caules de feijoeiros (Phaseolus vulgaris L.), inoculados com Curtobacterium flaccumfaciens pv. flaccumfaciens (Cff), mostraram alterações nos vasos de xilema em genótipos de feijoeiros altamente resistentes, como formação de estrutura semelhante a tilose e presença de fibrilas ao redor das células bacterianas. Em genótipos suscetíveis, Cff colonizou além de vasos de xilema, células parenquimáticas e metaxilema.

Palavras-chave adicionais: Phaseolus vulgaris, murcha-de-curtobacterium, microscopia eletrônica de transmissão.

\section{ABSTRACT}

Souza, V.L \& Maringoni, A.C. Ultraestructural analysis of Curtobacterium flaccumfaciens pv. flaccumfaciens in dry bean genotypes..Summa Phytopathologica, v.34, n.4, p.318-320, 2008

Transmission electron microscopy for observations of stem cells of bean (Phaseolus vulgaris L.), inoculated with Curtobacterium flaccumfaciens pv. flaccumfaciens (Cff) showed some alterations in the xylen vessels of highly resistant genotypes with formation of estruture like tyloses and occurrence of fibrillas envolving the bacterial cells. In susceptible genotypes, Cff colonized xylem vessels as well as vascular parenchyma cells and metaxylem vessels.

Keywords: Phaseolus vulgaris, bacterial wilt, transmission electron microscopy.

O cultivo de feijoeiro na região Centro-Sul do Brasil tem sido afetado por Curtobacterium flaccumfaciens pv. flaccumfaciens (Cff), agente causal da doença conhecida como murcha-de-curtobacterium ou murcha bacteriana, com sérios danos e prejuízos à produção. A doença foi constatada pela primeira vez no estado de São Paulo, em 1995 (7), e a partir de 2001, ela foi observada em diferentes regiões produtoras dos Estados do Paraná (6), Santa Catarina (6), Goiás e no Distrito Federal (11).

A colonização de Cff em feijoeiro ocorre em vasos de xilema (3). Nas sementes, a bactéria fica alojada nas células paliçádicas que formam a testa; sob condições de inoculação artificial, foi constatada a transmissão de até $52,5 \%$ em sementes de feijoeiro, além de seu efeito negativo sobre a germinação (1).

Dentre as várias técnicas disponíveis para o estudo da interação patógeno-hospedeiro, a microscopia eletrônica fornece detalhes estruturais úteis para tal estudo (3). A análise de vasos de xilema de feijoeiros altamente resistentes a Cff, sob microscopia eletrônica de varredura (MEV), mostrou várias aglutinações das bactérias envolvidas por filamentos e estruturas rendilhadas nas pontuações dos vasos do xilema, enquanto que em genótipos suscetívies, foi observada grande quantidade de células bacterianas colonizando os vasos de xilema (10).
Outra estrutura que confere resistência às plantas, em conseqüência da invasão sistêmica pelo patógeno, é a tilose nos vasos do xilema, que procura conter o avanço do patógeno (8).

Nos genótipos de feijoeiro altamente resistentes a $X$. axonopodis pv. phaseoli (Xap), constatou-se encapsulamento das células bacterianas; nos genótipos de feijoeiro moderadamente resistentes a Xap, foram observadas poucas bactérias nos espaços intercelulares e a presença de vesículas entre o plasmalema e a parede celular, enquanto que nos genótipos de feijoeiro suscetíveis a Xap, foi observado maior número de bactérias nos espaços intercelulares, condensação do citoplasma, desintegração de organelas, rompimento da lamela média e a penetração da bactéria no xilema (2). A colonização dos vasos de xilema de genótipos de pimentão suscetíveis e resistentes a Ralstonia solanacearum foi observada sob microscopia eletrônica de transmissão (MET) e revelaram a formação de fimbrilas nos vasos de xilema das plantas resistentes que limitaram a colonização da bactéria (9). O presente trabalho teve por objetivo avaliar a colonização de vasos de xilema de plantas de feijoeiro resistentes e suscetíveis a Cff sob MET.

Os ensaios foram conduzidos sob condições de casa-de-vegetação, no Departamento de Produção Vegetal da FCA, UNESP, campus de Botucatu. Foram utilizados quatro genótipos altamente resistentes 
(cultivar IAC Carioca Tybatã e acessos IAC 297, IAC 588 e IAC 592); quatro genótipos suscetíveis (cultivares Rosinha e Pérola e os acessos IAC 546 e IAC 586), com cinco repetições cada. As plântulas de feijoeiro foram conduzidas em vaso de $2 \mathrm{~L}$ contendo de substrato autoclavado. Em cada vaso foram mantidas três plantas e, aos nove dias após emergência, foram inoculadas com duas punções no caule, entre a folhas cotiledonares e as folhas primárias, com uma agulha entomológica previamente umedecida em colônias bacterianas, desenvolvidas em meio NSA, durante $96 \mathrm{~h}$ a $28{ }^{\circ} \mathrm{C}$. No tratamento testemunha, as plantas ao invés de inoculo bacteriano receberam água destilada. Os genótipos de feijoeiros selecionados neste estudo são representantes de uma amostra de 333 acessos pertencente ao Instituto Agronômico de Campinas (IAC), avaliados anteriormente (10).

Fragmentos de caules de feijoeiros com aproximadamente $8 \mathrm{~cm}$ foram coletados entre $4 \mathrm{~cm}$ acima e $4 \mathrm{~cm}$ abaixo do ponto de inoculação. As amostras foram processadas para MET, fixadas por 24 horas em solução de glutaraldeído a $4^{\circ} \mathrm{C}$, lavadas por três vezes em tampão fosfato $0,1 \mathrm{M} \mathrm{pH} \mathrm{7,3} \mathrm{(10} \mathrm{min),} \mathrm{pós-fixadas} \mathrm{por} 24 \mathrm{~h}$ com tetróxido de ósmio $2 \%$ em tampão fosfato $0,1 \mathrm{M}, \mathrm{pH} 7,3$, seguidos de desidratação em série com acetona $(50,70,90$ e $100 \%)$ e tratadas três vezes com óxido de propileno (15 min). A desidratação foi realizada com acetona 50,70 e $90 \%$, durante $10 \mathrm{~min}$, e com acetona $100 \%$, por três vezes, durante $15 \mathrm{~min}$. Em seguida os materiais foram imergidos em resina Epon/Araldita Lx-112, que foi deixada para polimerizar durante $48 \mathrm{~h}$, a $60^{\circ} \mathrm{C}$. De cada amostra foram obtidos cortes ultrafinos (“600A $\left.\mathrm{A}^{\circ}\right)$, submetidos à solução policromática contendo azul de toludina, fucsina básica e borato de sódio (4) e examinados em MET, marca Hitachi H-500, operado a $75 \mathrm{Kv}$.

Exames sob MEV mostraram que pontuações em vasos de xilema apresentavam-se cobertas por estruturas rendilhadas em feijoeiros resistentes a Cff, oito dias após inoculação (10). No presente trabalho, com análise mais detalhada, utilizando-se MET, permitiu observar projeções protoplasmáticas para o interior dos vasos de xilema em genótipos de feijoeiro resistentes a Cff (Figura 1), que sugere o início da formação de tilose; estas projeções se entrelaçam e formam as estruturas rendilhadas anteriormente observadas sob MEV (10). Nos genótipos altamente resistentes, essas projeções podem resultar na obstrução dos vasos de xilema e restringir a colonização de Cff. Segundo Pascholatti \& Leite (8), dentre as barreiras morfológicas induzidas pelas plantas em conseqüência da invasão sistêmica pelo patógeno, a mais freqüente é a

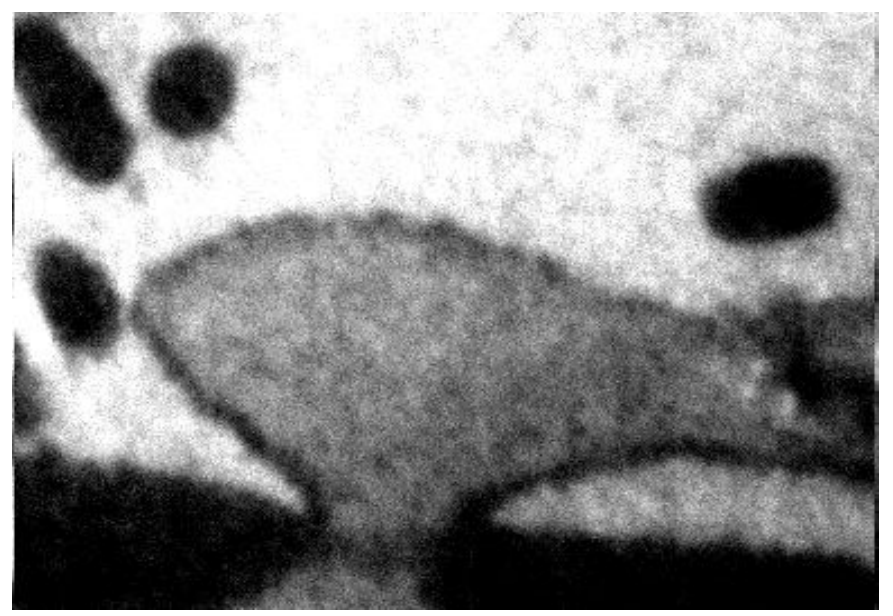

Figura 1. Projeção protoplasmática no interior do vaso de xilema em feijoeiro resistente a Curtobacterium flaccumfaciens pv. flaccumfaciens, sob microscopia eletrônica de transmissão.

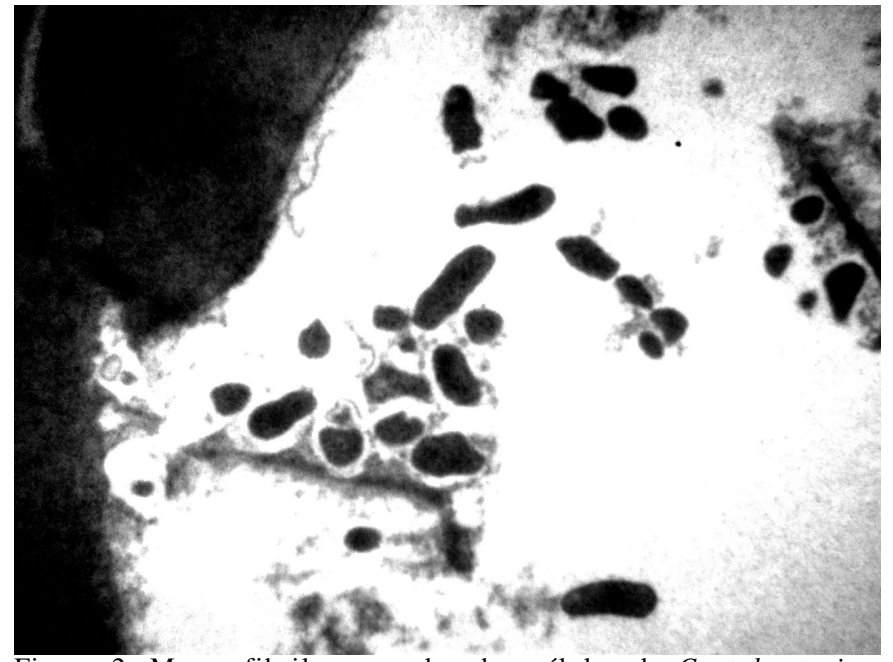

Figura 2. Massa fibrilar ao redor das células de Curtobacterium flaccumfaciens pv. flaccumfaciens em feijoeiro altamente resistente, acesso IAC 297, sob microscopia eletrônica de transmissão.

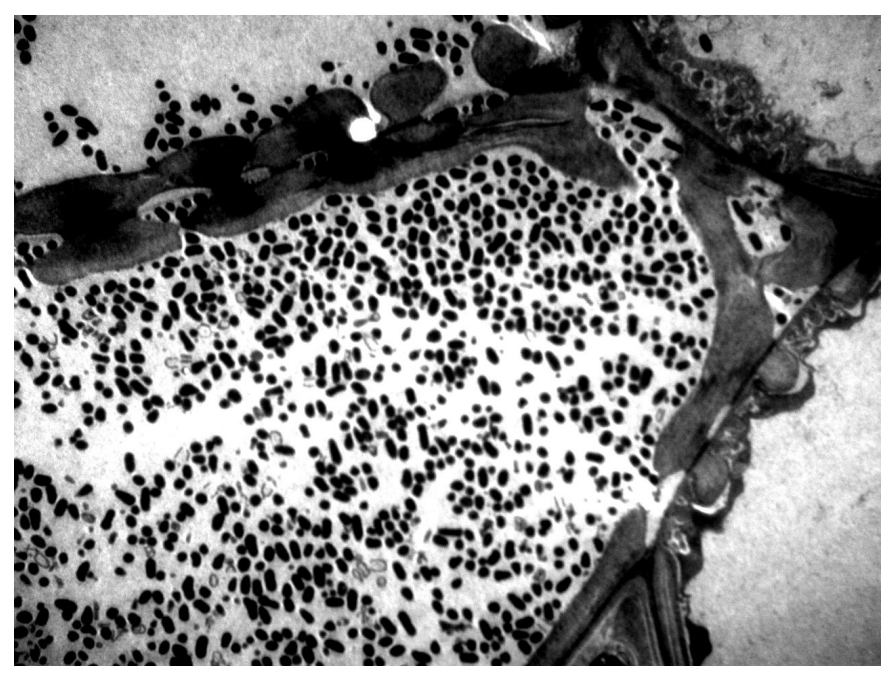

Figura 3. Curtobacterium flaccumfaciens pv. flaccumfaciens presente em vaso de xilema de feijoeiro suscetível, cultivar Rosinha, sob microscopia eletrônica de transmissão.

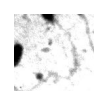

- $\begin{aligned} & x \\ & -2\end{aligned}$

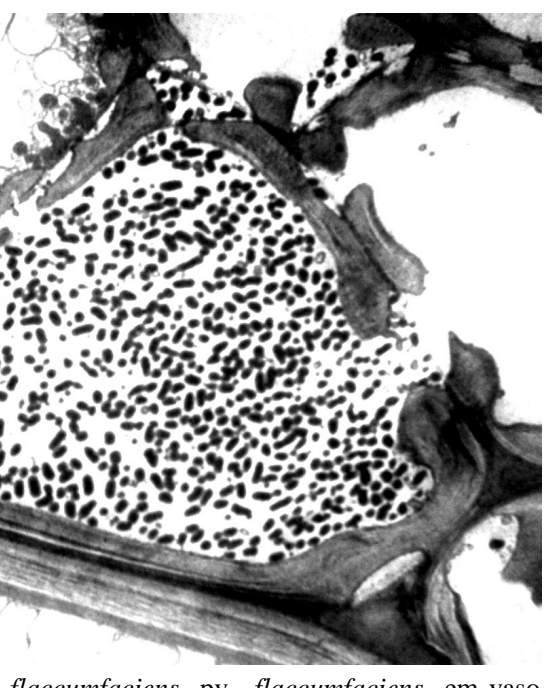

Figura 4. Curtobacterium flaccumfaciens pv. flaccumfaciens em vaso de xilema de feijoeiro suscetível, acesso 546, sob microscopia eletrônica de transmissão. 


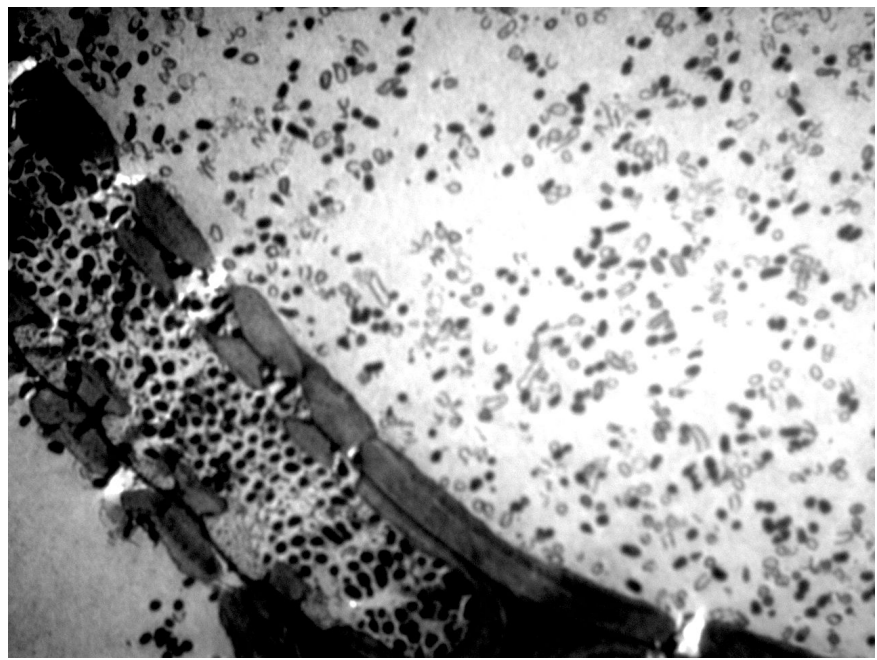

Figura 5. Pontoações na parede do vaso do xilema de feijoeiro suscetível a Curtobacterium flaccumfaciens pv. flaccumfaciens, acesso 586, observadas sob microscopia eletrônica de transmissão.

formação de tilose nos vasos do xilema.

No genótipo de feijoeiro altamente resistente, (IAC 297), foi constatada a presença de células de Cff nos vasos do xilema envolvidas por massa fibrilar (Figura 2), aos 28 dias após inoculação. Observações semelhantes foram constatadas por Rahman et al. (9), em estudos da com Ralstonia solanacearum e genótipos resistentes de pimentão, e por Horino et al. (5), em arroz resistentes e infectados por Xanthomonas campestris pv. oryzae.

A cultivar Rosinha e o acesso IAC 546 apresentaram grande quantidade de Cff nos vasos do xilema que atravessam as células parenquimáticas (Figuras 3 e 4). No acesso IAC 586, suscetível a Cff, Figura 5, evidencia-se a presença de Cff em vasos de xilema, no metaxilema e células parenquimáticas, aos 28 dias após inoculação. Observações semelhantes a essa foram encontradas em genótipos de feijoeiro suscetívies a $X$. axonopodis pv. phaseoli, 21 dias após a inoculação (2). A presença de grande quantidade de células bacterianas nos vasos de xilema, em genótipos de feijoeiro altamente suscetívies a Cff, ocasiona bloqueio no transporte da água, em conseqüência disto resulta os sintomas de murcha, amarelecimento, subdesenvolvimento e morte de plantas.

\section{REFERÊNCIAS BIBLIOGRÁFICAS}

1. Chavarro, C.A.; Lopez, G.C.A., Lenne, J.M. Características y pathogenicidad de Corynebacterium flaccumfaciens (Hedges) Dows. agente causal del marchitamiento bacteriano de Zornia spp. y su efecto en el rendimiento de Z. glaba CIAT 7847 y Phaseolus vulgaris. Acta Agronomica, Palmira, v.35, n. 2, p.6479, 1985.

2. Contreras, N.; Trujillo, G.; Borges, O.; Centeno, F. Análisis ultraestructural de la interacción de Xanthomonas axonopodis pv. phaseoli con genotipos resistentes, moderadamente resistentes y susceptibles de Phaseolus vulgaris L. Interciencia, Caracas, v.26, n.11, p. 554-557, 2001.

3. Dinensen, I.G. The movement of Corynebacterium flaccumfaciens in bean plants (Phaseolus vulgaris). In: International Conference on Plant Pathogenic Bacterial 4., 1978. Angers, Proceeding. Angers: INRA, 1978. v.2, p. 929-933.

4. Hopper G.R.; Baker, K.K.; Fleger, E.S.L. Exercises in electron microscopy: A laboratory Manual for Biology and Medicine. 1979. Appendix 6. MSU, p.118-121.

5. Horino, O.; Watanabe, M.; Funagai, M. Electron microscopic examination of fibrillar materials and bacterial lipopolysacharide observed in xylem vessels of rice leaves infected with Xanthomonas campestris pv. oryzae. Annals of the Phytopathological Society of Japan, Tokyo, v. 59, n.2, p.188-191, 1993.

6. Leite Júnior., R.P.; Meneguim, L.; Behlau, F.; Rodrigues, S.R.; Bianchini, A. Ocorrência de Curtobacterium flaccumfaciens subsp. flaccumfaciens em feijoeiro no Paraná e Santa Catarina. Fitopatologia Brasileira, Brasília, v.26, supl., p.303-304, 2001.

7. Maringoni, A.C. Rosa, E.F. Ocorrência de Curtobacterium flaccumfaciens pv. flaccumfaciens em feijoeiro no Estado de São Paulo. Summa Phytopathologica, Jaboticabal, v.23, n.2, p.160162,1997

8. Pascholati, S. F., Leite, B. Hospedeiro: mecanismo de resistência. In: Bergamin Filho, A., Kimati, H., Amorim, L. (Ed.) Manual de fitopatologia. São Paulo: Agronômica Ceres, 1995. v.1, p.417453.

9. Rahman, M. A.; Abdullah H.; Vanhaecke, M. Histopathology of susceptible and resistant Capsicum annuum cultivar infected with Ralstonia solanacearum. Journal of Phytopathology, Berlim, v.147, p.129-140, 1999.

10. Souza, V. L.; Maringoni, A. C.; Carbonell, S. A. M.; Ito, M. F. Resistência genética em genótipos de feijoeiro a Curtobacterium flaccumfaciens pv. flaccumfaciens. Summa Phytopathologica, Botucatu, v. 32, n.4, p.339-344, 2006.

11. Uesugi, C. H.; Freitas, M. A.; Menezes, J. R.. Ocorrência de Curtobacterium flaccumfaciens pv. flaccumfaciens em feijoeiro, em Goiás e no Distrito Federal. Fitopatologia Brasileira, Brasília, v.28, n.3, p.324, 2003. 